\title{
CONSTRUÇÃo DE UMA CELA DE FLUXO DE LONGO CAMINHO ÓPTICO PARA MEDIDAS ESPECTROFOTOMÉTRICAS
}

\author{
Wanessa Roberto Melchert e Fábio R. P. Rocha* \\ Instituto de Química, Universidade de São Paulo, CP 26077, 05513-970 São Paulo - SP, Brasil \\ Ivo M. Raimundo Jr. \\ Instituto de Química, Universidade Estadual de Campinas, CP 6154, 13084-971 Campinas - SP, Brasil \\ Boaventura F. Reis \\ Centro de Energia Nuclear na Agricultura, Universidade de São Paulo, CP 96, 13400-970 Piracicaba - SP, Brasil
}

Recebido em 20/4/07; aceito em 27/7/07; publicado na web em 26/2/08

\begin{abstract}
CONSTRUCTION OF A LONG-PATHLENGTH FLOW CELL FOR SPECTROPHOTOMETRIC MEASUREMENTS. A simple and low-cost flow cell with $30 \mathrm{~cm}$ optical path for spectrophotometric measurements is described. It presents desirable characteristics such as low attenuation of the radiation beam and internal volume $(75 \mu \mathrm{L})$ comparable to that of a 1-cm conventional cell $(80 \mu \mathrm{L})$. Despite the increase in optical path, the effect on sample dispersion was also similar to that attained in the commercial cell. The performance of the cell was assessed by the determination of phosphate based on the molybdenum blue method, yielding a linear response range between 0.05 and $0.8 \mathrm{mg} \mathrm{L}^{-1}$ phosphorus ( $\left.\mathrm{r}=0.999\right)$. The increase in sensitivity (30.4-fold) in comparison with that obtained with a conventional $1-\mathrm{cm}$ flow cell agreed with that estimated by the Lambert-Beer law.
\end{abstract}

Keywords: long pathlength spectrophotometry; flow analysis; liquid core waveguide.

\section{INTRODUÇÃO}

A espectrofotometria UV-Vis tem sido amplamente utilizada em aplicações analíticas por sua robustez, custo relativamente baixo e grande número de procedimentos desenvolvidos. Porém, vários métodos espectrofotométricos apresentam limitações de sensibilidade. Este panorama pode ser ilustrado pela comparação das concentrações máximas toleradas de poluentes no ambiente, de acordo com a resolução CONAMA n ${ }^{\circ} 357 / 2005^{1}$, com os limites de quantificação de procedimentos espectrofotométricos oficiais ${ }^{2}$. Diversas estratégias têm sido propostas para aumento de sensibilidade em espectrofotometria UV-Vis, como a formação de produtos com maiores absortividades molares, o aumento do caminho óptico das celas de medida ou a concentração da espécie a ser detectada em uma etapa prévia ou mesmo simultânea à detecção ${ }^{3}$.

De acordo com a lei de Lambert-Beer, a absorbância é proporcional ao caminho óptico da cela de medida, devido ao aumento do número de espécies absorventes que interagem com o feixe de radiação. Entretanto, em celas construídas com materiais convencionais, o aumento do caminho óptico é limitado pela excessiva atenuação do feixe de radiação e aumento do volume interno ${ }^{4}$. Muitos esforços têm sido destinados à resolução destes inconvenientes, por exemplo, pela utilização de capilares com reduzido volume ou de celas de multi-reflexão ${ }^{3}$. Neste sentido, um dos principais avanços consistiu no desenvolvimento de um fluoropolímero amorfo, o Teflon AF- $2400^{\circledR}$, transparente na região entre 200 e 2000 nm e que apresenta índice de refração $(1,29)$ menor que o da água $(1,33)^{5}$. Um tubo constituído por este material pode se comportar como guia de ondas quando preenchido com soluções aquosas diluídas ${ }^{6}$, uma vez que a radiação pode ser conduzida por longos caminhos devido ao fenômeno de reflexão interna total. Como consequiência, limites de detecção da ordem de nmol L $\mathrm{L}^{-1}$ têm sido relatados em procedimentos utilizando celas de fluxo comerciais ${ }^{7-9}$.

*e-mail: frprocha@iq.usp.br
Neste trabalho, é proposta a construção de uma cela de fluxo com caminho óptico de $30 \mathrm{~cm}$ e volume interno reduzido, visando a melhoria de sensibilidade em sistemas de análises em fluxo com detecção espectrofotométrica.

\section{PARTE EXPERIMENTAL}

\section{Descrição da cela de longo caminho óptico}

A cela de fluxo foi construída com um tubo de Teflon AF-2400 ${ }^{\circledR}$ com $30 \mathrm{~cm}$ de comprimento, 0,6 mm de diâmetro interno e aproximadamente $75 \mu \mathrm{L}$ de volume (Biogeneral, USA) ${ }^{10}$. Adaptadores construídos em acrílico foram utilizados para o alinhamento das fibras ópticas com o guia de ondas e para entrada e saída de soluções, conforme a Figura 1a. Os blocos de acrílico foram presos por 2 parafusos e um filme de poliéster (transparência para retroprojetor) foi utilizado para separar a solução do interior do guia de ondas das fibras ópticas (Figura 1b). Os dispositivos foram arranjados e acondicionados em uma caixa para evitar a incidência de radiação eletromagnética UV-vis externa.

\section{Reagentes e soluções}

Todas as soluções foram preparadas empregando água deionizada e reagentes com grau analítico. Solução de molibdato de amônio 2,5 mmol $\mathrm{L}^{-1}$ foi preparada em meio de ácido nítrico $0,2 \mathrm{~mol} \mathrm{~L}^{-1}\left(\mathrm{R}_{1}\right)$. Solução de ácido ascórbico 2,5\% (m/v), $\mathrm{R}_{2}$, foi preparada em água. Soluções de referência de fósforo foram preparadas por diluições da solução estoque de $1000 \mathrm{mg} \mathrm{L}^{-1}$. Soluções de permanganato de potássio foram preparadas por diluições de uma solução estoque $1000 \mathrm{mg} \mathrm{L}^{-1}$.

\section{Equipamentos}

O módulo de análise foi construído empregando tubos de polietileno $(0,8 \mathrm{~mm}$ d.i. $)$ e confluências feitas de acrílico. A propul- 


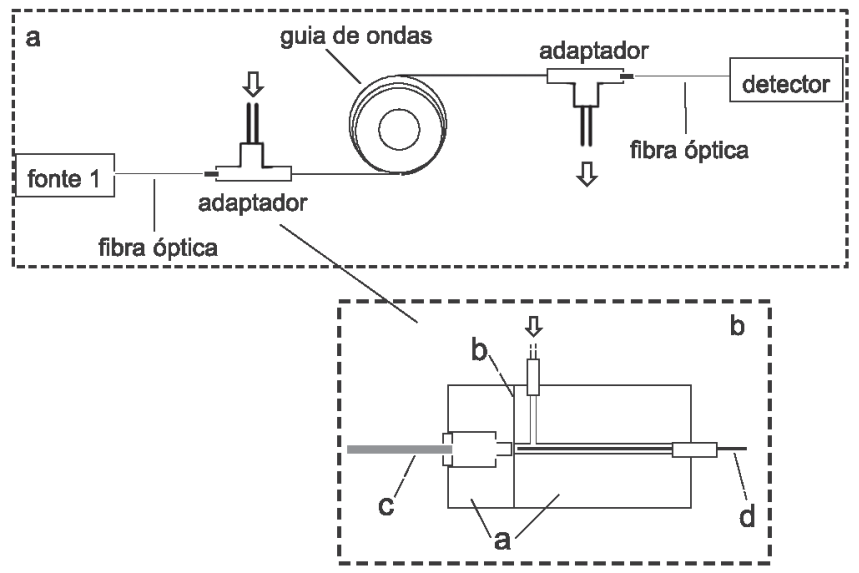

Figura 1. (a) Arranjo para medidas por espectrofotometria com longo caminho óptico. As setas indicam os pontos para entrada e saída de soluções; (b) vista em corte de um dos adaptadores. a: blocos de acrílico $(6,0 \mathrm{~cm}$ comprimento $\times$ 4,0 cm largura $\times 2,0 \mathrm{~cm}$ altura) presos por 2 parafusos (não mostrados nas Figura); b: filme de poliéster; c: cabo de fibra óptica e d: guia de ondas (Teflon $A F-2400^{\circledR}$ )

são dos fluidos foi efetuada por uma bomba peristáltica IPC-4 (Ismatec, Suíça) equipada com tubos de Tygon. Um injetor proporcional com barra deslizante foi empregado para a inserção das soluções. Cabos de fibra óptica (Ocean Optics, USA) foram utilizados para o transporte da radiação proveniente de uma lâmpada de tungstênio-halogênio (Ocean Optics, LS-1) até a cela de fluxo e da saída desta até o sistema de detecção - espectrofotômetro multicanal com um arranjo linear de 2048 fotodetectores do tipo CCD (Ocean Optics, USB 2000). Uma cela de fluxo de $1 \mathrm{~cm}$ de caminho óptico e volume de $80 \mu \mathrm{L}$ (Hellma, Alemanha) foi empregada em experimentos para comparação de resultados.

\section{Diagramas de fluxos e procedimento}

O desempenho da cela proposta foi avaliado empregando-se soluções de permanganato de potássio e o método do azul de molibdênio para determinação de fosfato. Um sistema de análises em fluxo em linha única (volume da amostra $=80 \mu \mathrm{L}$, vazão do transportador $=$ $2,4 \mathrm{~mL} \mathrm{~min}^{-1}$ e reator helicoidal de $50 \mathrm{~cm}$ ) foi empregado nos experimentos com permanganato de potássio (medidas em $525 \mathrm{~nm}$ ). Para a determinação de fosfato, foi empregado um módulo de análises com adição de reagentes por confluência. As soluções de fosfato (volume da amostra $=250 \mu \mathrm{L}$ ) foram inseridas no fluido transportador $\left(\mathrm{H}_{2} \mathrm{O}, 4,0 \mathrm{~mL} \mathrm{~min}^{-1}\right)$, recebendo por confluência as soluções de molibdato de amônio $\left(\mathrm{R}_{1}\right)$ e ácido ascórbico $\left(\mathrm{R}_{2}\right)$, fluindo a $1,0 \mathrm{~mL}$ $\mathrm{min}^{-1}$. Foi empregado um reator helicoidal $\mathrm{com} 100 \mathrm{~cm}$ de comprimento e as medidas espectrofotométricas foram realizadas em 660 $\mathrm{nm}$. Em ambos os sistemas de análises em fluxo, água foi empregada como fluxo transportador.

\section{DESEMPENHO DA CELA PROPOSTA}

Foram obtidos sinais transientes com soluções de permanganato de potássio empregando a cela proposta e uma cela comercial com caminho óptico de $1 \mathrm{~cm}$. Mesmo aumentando o caminho óptico em 30 vezes, os volumes internos das celas são aproximadamente iguais (75 e $80 \mu \mathrm{L}$ para as celas de 30 e $1 \mathrm{~cm}$, respectivamente), o que não altera substancialmente a dispersão da amostra e o tempo de limpeza (14 e $18 \mathrm{~s}$ para cela de 1 e $30 \mathrm{~cm}$, respectivamente). A altura do sinal transiente obtido para uma solução $5,00 \mathrm{mg} \mathrm{L}^{-1} \mathrm{KMnO}_{4}$ utili- zando a cela de $30 \mathrm{~cm}$ foi ca.18\% maior em relação ao sinal obtido com solução $100 \mathrm{mg} \mathrm{L}^{-1} \mathrm{KMnO}_{4}$ com a cela de $1 \mathrm{~cm}$.

$\mathrm{O}$ desempenho da cela proposta também foi avaliado na presença de reações químicas, explorando a determinação de fosfato pelo método do azul de molibdênio. Sinais transientes obtidos com celas de 1 e $30 \mathrm{~cm}$ são mostrados na Figura 2. Resposta linear foi observada entre 0,05 e $0,8 \mathrm{mg} \mathrm{L}^{-1}$ fósforo $(\mathrm{r}=0,999)$ para cela de $30 \mathrm{~cm}$, enquanto para cela de $1 \mathrm{~cm}$ a resposta linear foi de $2,0-10,0 \mathrm{mg} \mathrm{L}^{-1}$ fósforo $(\mathrm{r}=0,997)$. O aumento de sensibilidade foi estimado em 30,4 vezes, o que está de acordo com o esperado pela lei de Lambert-Beer. O limite de quantificação estimado com a cela construída é compatível com o limite máximo permitido pela resolução do CONAMA n ${ }^{\circ} 357 / 2005^{1}$ para fósforo em águas $\left(0,020-0,1 \mathrm{mg} \mathrm{L}^{-1}\right)$.
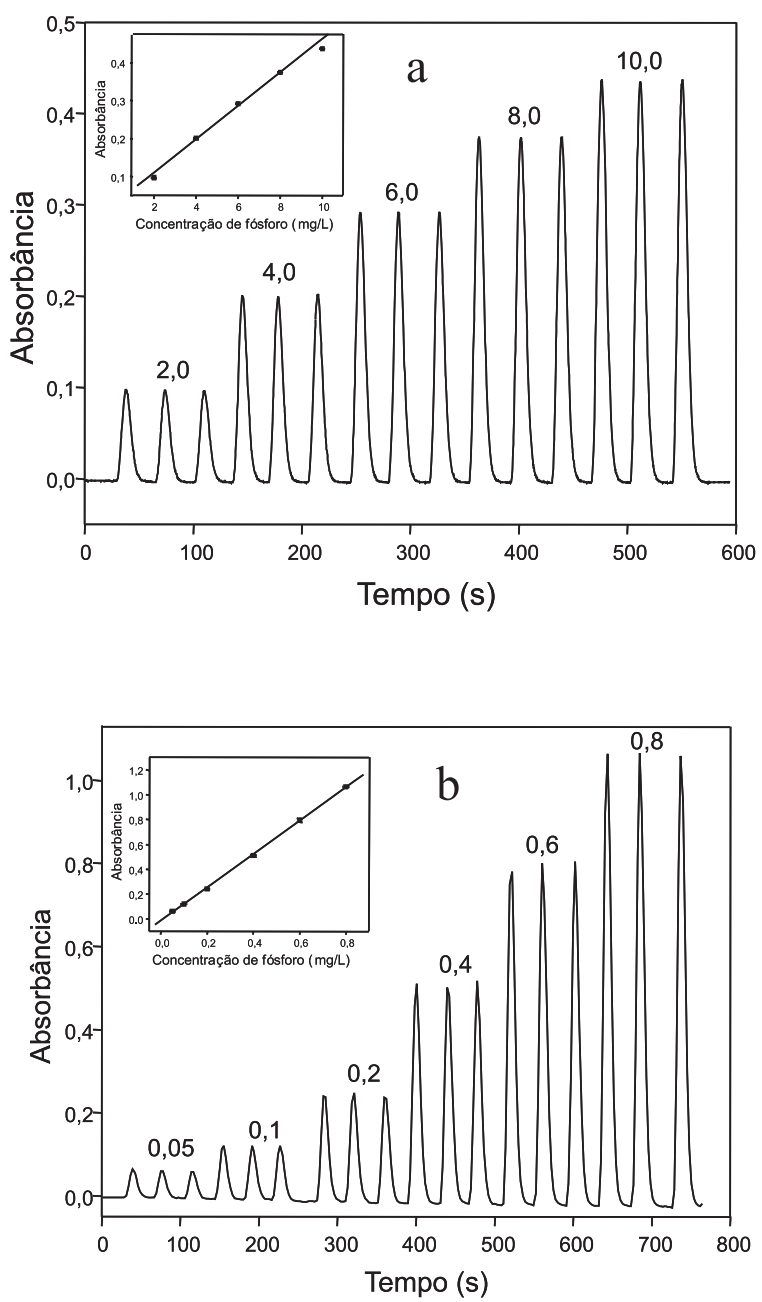

Figura 2. Sinais transientes para determinação de fosfato com cela de caminho óptico de (a) $1 \mathrm{cme} \mathrm{(b)} 30 \mathrm{~cm}$. Os números indicam as concentrações de fósforo em $\mathrm{mg} \mathrm{L}^{-1}$. As figuras inseridas mostram a relação linear entre absorbância e concentração

\section{CONCLUSÕES}

A cela de longo caminho óptico proposta pode ser facilmente construída e é de baixo custo em comparação com uma cela comercial de $100 \mathrm{~cm}$ de caminho óptico com custo aproximado de US\$ 1700 (Ocean Optics) ${ }^{11}$ e cela de $1 \mathrm{~cm}$ com custo aproximado de US\$ 900 (Hellma) ${ }^{12}$. A cela apresenta características desejáveis como volume reduzido e caminho óptico ampliado, com baixa ate- 
nuação do feixe de radiação. Adicionalmente, o coeficiente de dispersão é comparável ao estimado para uma cela de fluxo convencional com $1 \mathrm{~cm}$ de caminho óptico e $80 \mu \mathrm{L}$ de volume.

Volume de amostra de ca. $100 \mu \mathrm{L}$ é suficiente para medidas em procedimentos em batelada, empregando, por exemplo, uma seringa hipodérmica para introdução das soluções das amostras. A cela construída pode ser utilizada com sistemas de detecção mais simples com o alinhamento do tubo de Teflon AF- $2400^{\circledR}$ a um diodo emissor de luz (LED) e a um fotodetector através dos blocos de acrílico. É também possível a adaptação da cela proposta a espectrofotômetros comerciais. Medidas por fluorescência podem ser efetuadas empregando LEDs posicionados perpendicularmente ao tubo como fontes de excitação, tal como proposto por Dallas e Dasgupta $^{13}$.

\section{AGRADECIMENTOS}

Às agências de fomento FAPESP e CNPq pelas bolsas e auxílios concedidos.

\section{REFERÊNCIAS}

1. Conselho Nacional do Meio Ambiente (CONAMA), Resolução No 357, de 17 de março de 2005, http://www.mma.gov.br/port/conama/res/res05/ res35705.pdf, acessada em Abril 2007.

2. Eaton, A. D.; Clesceri, L. S.; Greenberg, A. E.; Standard Methods for the Examination of Water and Wastewater, $19^{\text {th }}$ ed., American Public Health Association: Washington, 1995.

3. Rocha, F. R. P.; Teixeira, L. S. G.; Quim. Nova 2004, 27, 807.

4. Lei, W.; Fujiwara, K.; Fuwa, K.; Anal. Chem. 1983, 55, 951.

5. Dasgupta, P. K.; Genfa, Z.; Poruthoor, S. K.; Caldwell, S.; Dong, S.; Anal. Chem. 1998, 70, 4661.

6. Byrne, R. H.; Yao, W.; Kaltenbacher, E.; Waterbury, R. D.; Talanta 2000, 50, 1307.

7. Lupetti, K. O.; Rocha, F. R. P.; Fatibello-Filho, O.; Talanta 2004, 62, 463.

8. Gimbert, L. J.; Haygarth, P. M.; Worsfold, P. J.; Talanta 2007, 71, 1624.

9. Yao, W.; Byrne, R. H.; Waterbury, R. D.; Environ. Sci. Technol. 1998, 32, 2646.

10. http://www.biogeneral.com, acessada em Março 2007.

11. http://www.oceanoptics.com, acessada em Março 2007.

12. http://www.hellma.com, acessada em Março 2007.

13. Dallas, T.; Dasgupta, P. K.; Trends Anal. Chem. 2004, 23, 385. 